\title{
BMJ Open A nationwide study of patients hospitalised for poisoning in Korea based on Korea National Hospital Discharge In-Depth Injury Survey data from 2005 to 2009
}

\author{
Kyunghee Kim, ${ }^{1}$ Jae Wook Choi, ${ }^{1,2,3}$ Miso Park, ${ }^{1}$ Min Soo Kim, ${ }^{1}$ Eun Sun Lee ${ }^{1}$
}

To cite: Kim K, Choi JW, Park M, et al. A nationwide study of patients hospitalised for poisoning in Korea based on Korea National Hospital Discharge In-Depth Injury Survey data from 2005 to 2009. BMJ Open 2015;5: e008823. doi:10.1136/ bmjopen-2015-008823

- Prepublication history for this paper is available online. To view these files please visit the journal online (http://dx.doi.org/10.1136/ bmjopen-2015-008823).

Received 19 May 2015 Revised 7 October 2015 Accepted 16 October 2015

CrossMark

\footnotetext{
${ }^{1}$ Institute for Occupational and Environmental Health, Korea University, Seoul, Korea

${ }^{2}$ Graduate School of Public Health, Korea University,

Seoul, Korea

${ }^{3}$ Department of Preventive Medicine, Korea University College of Medicine, Seoul, Korea
}

Correspondence to Dr Jae-Wook Choi; shine@korea.ac.kr

\section{ABSTRACT}

Objectives: In light of the need to develop an integrated database on poisoning incidents in Korea, this study seeks to determine the characteristics of poisoning incidents in Korea by age, gender, location of incident, causative substance and patient prognosis.

Data sources: The Korea National Hospital Discharge In-Depth Injury Survey results (2005-2009) from the Korea Centers for Disease Control and Prevention were used.

Participants: 3826 participants in the survey who had been hospitalised for poisoning incidents.

Results: The poisoning hospitalisation rate per 100000 population was higher in women (1.735) than in men (1.372) and increased with age: the rate was 0.458 among individuals aged $\leq 9$ years, 0.481 among those aged 10-19 years, 1.584 among those aged 20-64 years and 4.053 among those aged $\geq 65$ years. The intentional poisoning hospitalisation rate differed by gender and age group. Women aged $\leq 19$ years and 20-64 years showed a higher hospitalisation rate than men, while men aged $\geq 65$ years showed a higher hospitalisation rate than women in the same age group. The most common poisoning substance was pesticides $(33.6 \%)$, while antiepileptic, sedativehypnotic and antiparkinsonism drugs and psychotropic drugs, not elsewhere classified were also very common. Poisoning in those aged $\leq 9$ years usually involved other drugs, while pesticides were the most common substances in those aged 20-64 years and $\geq 65$ years.

Conclusions: This study analysed poisoning incidents in Korea from 2005 to 2009, by age and gender, causative substance, and characteristics. The results of this study may serve as evidence for new strategies in Korea to prevent poisoning.

\section{INTRODUCTION}

Poisoning incidents are considered a major public health issue worldwide. ${ }^{2}$ The USA, member countries of the European Union (EU) and some developing countries

\section{Strengths and limitations of this study}

- This study used data from the Korea National Hospital Discharge In-Depth Injury Survey conducted by the Korea Control of Diseases and Prevention to characterise poisoning incidents.

- Unlike previous studies which partially analysed poisoning incidence in Korea, this study offers a comprehensive and nationally representative overview thereof.

- Poisoning patients who attended clinics with under 100 beds and did not go to hospital were not considered in this study.

operate national poison information centres to gather and make public statistical information on poisoning incidents. Recently, incidents caused by chemicals have been emerging as a social issue in South Korea. A national database on accidental chemical intoxication that reflects the current state has yet to be established in Korea, despite the increase in the risk of and number of poisoning incidents. ${ }^{3}$

The American Association of Poison Control Centers (AAPCC) reported 3624063 telephone calls regarding poisoning incidents in 2011, ${ }^{4}$ while the UK's National Poisons Information Service (NPIS) reported 53796 calls in 2012 and 2013. In addition, Ireland's National Poisons Information Centre (NPIC) reported that 9563 enquiries concerning poisoning incidents were made in $2012 .{ }^{6}$ Estonia's National Poisoning Information Centre reported that children between 1 and 6 years of age accounted for $47 \%$ (420 cases) of the 1118 poisoning incidents reported in 2012. ${ }^{7}$ The Swedish Poisons Information Centre analysed 86397 poisoning incidents in 2014 and reported that children aged 10 and under 
accounted for $34 \%$ of all incidents, while the causative substances, in descending order, were chemical products $(41 \%)$, pharmaceuticals $(28 \%)$, plants $(11 \%)$, cosmetics $(8 \%)$ and tobacco $(4 \%){ }^{8}$

Unlike the countries mentioned above, due to the absence in Korea of a poisoning information management centre, it is hard to accurately perform an epidemiological statistical analysis, and thus difficult to determine the frequency of and substances involved in poisonings in Korea. Studies on poisoning incidents in Korea include one that reported a mortality rate of 8.70 per 100000 inhabitants, ${ }^{9}$ a study on the economic burden of acute pesticide poisoning, a report analysing patients presenting in emergency rooms with pesticide poisoning, and research analysing causative substances and patient prognoses in those with cardiac arrest caused by poisoning before hospital presentation. ${ }^{10-12}$

Most studies analysing poisoning incidents in Korea have focused on identifying causative substances and the characteristics of patients presenting to hospital or emergency care centres. As such, these studies are not comprehensive, making it difficult to examine the causative substances and patient prognosis. In addition, there are few studies on the characteristics of and causative substances used in intentional poisoning, which is reported to represent a high percentage of unnatural deaths. ${ }^{13}$ The Korea Centers for Disease Control and Prevention and the Ministry of Health and Welfare have been conducting an in-depth national hospital discharge injury survey since 2004 for time-series analysis of discharged poisoning incident patients. ${ }^{14}$

Using data from the National Hospital Discharge In-Depth Injury Survey conducted by the Korea Centers for Disease Control and Prevention, this study aimed to describe the status of poisoning incidents in Korea. The goals of this study were to analyse: (1) the characteristics of incidents according to age, gender, location and intentionality; (2) the causative substances used by each age group; (3) the prognoses in each age group; and finally, (4) differences in age, gender and causative substances between intentional and unintentional poisonings.

\section{METHODS}

\section{Data selection for analysis of poisoning incidents in Korea}

The Korea Centers for Disease Control and Prevention has performed an in-depth discharge injury survey since 2005, using the NHDS (National Hospital Discharge Survey) methodology of the USA. The discharge injury in-depth survey investigates patients discharged in the previous year from general hospitals with more than 100 beds by selecting 170 sample hospitals by city/province and hospital size. Items investigated include the characteristics of the hospital (location, number of beds), major diagnosis of the patient, surgery, hospitalisation route, information after discharge and causative substances in cases of accidental poisoning.
The age distribution of patients included in the in-depth discharge survey corresponded with that of discharged patients in patient survey data obtained from hospital-level medical institutions in Korea. This indicates that the discharge injury in-depth survey can be used to obtain comprehensive and representative data according to age group to identify the characteristics of patients hospitalised due to poisoning incidents. ${ }^{15}$ This study analysed 3826 patients from 2005 to 2009 who met diagnosis codes for poisoning in the in-depth discharge survey data.

\section{Characteristics of hospitalised poisoning patients and hospitalisation rate}

Analysis of patients hospitalised due to poisoning was based on age, gender, hospitalisation route (emergency or outpatient department), location of the incident (eg, home, farm, beach, outdoors) and intentionality of the incident (intentional, unintentional or other poisoning). The hospitalisation rates due to intentional and unintentional poisoning for each age group and gender were estimated by dividing the total number of patients hospitalised from 2005 to 2009 by the total summed population for those years (total population: 246356 493; total male population: 123457323 ; total female population: 122899 170).

\section{Analysis of causative substances in cases of accidental poisoning}

Based on the opinions of emergency physicians, patients were classified under codes T36-T65 of the International Classification of Diseases, 10th Revision (ICD-10). ${ }^{16}$ Poisoning substances were classified as follow: narcotics and psychodysleptics (hallucinogens) (T40), antiepileptic, sedative-hypnotic and antiparkinsonism drugs, and psychotropic drugs, not elsewhere classified (T42, T43), diuretics and other unspecified drugs, medicaments and biological substances (T50), alcohol (T51), organic solvents, hydrocarbons and metals, etc (T52-T53, T56T57), corrosive substances (T54), soaps and detergents (T55), carbon monoxide (T58), gases (T59), pesticides (T60), seafood and food (T61-T62, T64), contact with venomous animals (T63), unspecified substances (T65) and other drugs (T36-T39, T41, T44-T49).

\section{Calculation of hospitalisation rate per 100000 population and other statistical analyses}

Analysis of patients hospitalised due to poisoning was performed using SPSS V.18.0 software. First, a frequency analysis and a descriptive analysis were performed to examine socio-demographic characteristics. Second, a frequency analysis was performed to examine differences in causative substances by age group $(\leq 19,20-64$ and $\geq 65$ years old), patient prognosis and intentionality. Third, to determine the overall hospitalisation rate per 100000 population and gender and age-specific hospitalisation rates, the total number of poisoning patients was divided by the total population from 2005 to 2009 . 
The $95 \%$ CIs for each value were calculated as follows:

$$
95 \% \mathrm{CI}=\mathrm{p} \pm 1.96 \sqrt{(\mathrm{pq} / \mathrm{n})}
$$

where $\mathrm{p}$ is case/population, and $\mathrm{q}$ is $1-\mathrm{p}$.

\section{RESULTS}

General characteristics of poisoning patients and poisoning hospitalisation rate per 100000 population

Overall, 3826 poisoning patients were identified from 2005 to 2009 , with more women $(2132,55.7 \%)$ than men $(1694,44.3 \%)$. Of these, 2566 were 20-64 years old, accounting for $67.1 \%$ of all poisoning patients. The hospitalisation rate among all poisoning incidents per 100000 population was 1.372 (95\% CI 1.307 to 1.437 ) in men and 1.735 (95\% CI 1.661 to 1.808 ) in women. The hospitalisation rate per 100000 population was 0.458 (95\% CI 0.376 to 0.539 ) in patients $\leq 9$ years of age, $0.481(95 \%$ CI 0.407 to 0.555$)$ in patients $10-19$ years of age, 1.584 (95\% CI 1.523 to 1.646 ) in patients $20-64$ years of age and 4.053 (95\% CI 3.799 to 4.307$)$ in patients $\geq 65$ years of age. Regarding hospitalisation route, 3553 people $(92.9 \%)$ were admitted through emergency rooms. More patients (2171) were hospitalised for intentional poisoning than for unintentional poisoning (table 1).
Causative poisoning substance for each age group (2005-2009)

Analysis of the causative substances in poisoning cases from 2005 to 2009 showed that incidents were most commonly caused by pesticides (T60) with 1284 cases $(33.6 \%)$, followed by 847 cases $(22.1 \%)$ caused by antiepileptic, sedative-hypnotic, antiparkinsonism drugs, and psychotropic drugs, not elsewhere classified (T42, T43), and 512 cases $(13.4 \%)$ caused by contact with a venomous animal (T63). Further analysis was performed regarding age group. In the $\leq 9$ year-old age group, other drugs (T36-T39, T41, T44-T49) were the most common causative substances (28 cases, 23.1\%), followed by antiepileptic, sedative-hypnotic, antiparkinsonism drugs and psychotropic drugs, not elsewhere classified (T42, T43) (18 cases, 14.9\%) and then pesticides (14 cases, $11.6 \%)$. In the 10-19-year-old age group, other drugs (T36-T39, T41, T44-T49) were the most common causative substances (74 cases, $45.4 \%)$, followed by antiepileptic, sedative-hypnotic, antiparkinsonism drugs, and psychotropic drugs, not elsewhere classified (32 cases, 19.6\%), and then pesticides (T60) (17 cases, $10.4 \%)$. In the $20-64$-year-old age group, pesticides were the most common causative substances $(839$ cases, $32.7 \%$ ), followed by antiepileptic, sedativehypnotic, antiparkinsonism drugs, and psychotropic drugs, not elsewhere classified (621 cases, 24.2\%), and

Table 1 General characteristic of poisoning patients and poisoning hospitalisation rate (per 100000 population) $(\mathrm{N}=3826)$

\begin{tabular}{|c|c|c|c|}
\hline & $\mathbf{N}$ & Per cent & Hospitalisation rate (per 100 000) \\
\hline \multicolumn{4}{|l|}{ Gender } \\
\hline Male & 1694 & 44.3 & $1.372(95 \% \mathrm{Cl} 1.307$ to 1.437$)$ \\
\hline Female & 2132 & 55.7 & 1.735 (95\% Cl 1.661 to 1.808$)$ \\
\hline \multicolumn{4}{|l|}{ Age (years) } \\
\hline$\leq 9$ & 121 & 3.2 & $0.458(95 \% \mathrm{Cl} 0.376$ to 0.539$)$ \\
\hline 10 to 19 & 163 & 4.3 & $0.481(95 \% \mathrm{Cl} 0.407$ to 0.555$)$ \\
\hline 20 to 64 & 2566 & 67.1 & $1.584(95 \% \mathrm{Cl} 1.523$ to 1.646$)$ \\
\hline$\geq 65$ & 976 & 25.5 & $4.053(95 \% \mathrm{Cl} 3.799$ to 4.307$)$ \\
\hline \multicolumn{4}{|l|}{ Admission route } \\
\hline Emergency & 3553 & 92.9 & - \\
\hline Outpatient & 272 & 7.1 & - \\
\hline Undetermined & 1 & 0.03 & - \\
\hline \multicolumn{4}{|l|}{ Outcome } \\
\hline Home care & 3075 & 80.4 & - \\
\hline Transferred to other hospital & 347 & 9.1 & - \\
\hline Death & 313 & 8.2 & - \\
\hline Undetermined & 91 & 2.4 & - \\
\hline \multicolumn{4}{|l|}{ Place of occurrence } \\
\hline Home & 2222 & 58.1 & - \\
\hline Farm & 244 & 6.4 & - \\
\hline Beach, outdoors & 175 & 4.6 & - \\
\hline Other & 235 & 6.1 & - \\
\hline Unknown & 950 & 24.8 & - \\
\hline \multicolumn{4}{|l|}{ Intent } \\
\hline Unintentional & 1361 & 35.6 & - \\
\hline Intentional & 2171 & 56.7 & - \\
\hline Other & 258 & 6.7 & - \\
\hline Unknown & 36 & 0.94 & - \\
\hline
\end{tabular}


Table 2 Causative substance (agent) of poisoning for each age group (2005-2009) (N=3826)

\begin{tabular}{|c|c|c|c|c|c|}
\hline \multirow[b]{2}{*}{ Causative substance (agent) } & \multicolumn{4}{|c|}{ Age (years) } & \multirow[b]{2}{*}{ Total } \\
\hline & $\begin{array}{l}\leq 9 \\
N(\%)\end{array}$ & $\begin{array}{l}10-19 \\
N(\%)\end{array}$ & $\begin{array}{l}20-64 \\
N(\%)\end{array}$ & $\begin{array}{l}\geq 65 \\
N(\%)\end{array}$ & \\
\hline \multicolumn{6}{|l|}{ Drugs, medicaments and biological substances } \\
\hline Other drugs (T36-T39, T41, T44-T49) & $28(23.1)$ & $74(45.4)$ & $353(13.8)$ & $58(5.9)$ & $513(13.4)$ \\
\hline Drugs and psychodysleptics (Т39) & $0(0.0)$ & $1(0.6)$ & $5(0.2)$ & $1(0.1)$ & $7(0.2)$ \\
\hline $\begin{array}{l}\text { Antiepileptic, sedative-hypnotic and antiparkinsonism drugs, } \\
\text { psychotropic drugs, not elsewhere classified (T42, T43) }\end{array}$ & $18(14.9)$ & $32(19.6)$ & $621(24.2)$ & $176(18.0)$ & $847(22.1)$ \\
\hline $\begin{array}{l}\text { Diuretics and other and unspecified drugs, medicaments and } \\
\text { biological substances (T50) }\end{array}$ & $13(10.7)$ & $11(6.7)$ & $63(2.5)$ & $24(2.5)$ & $111(2.9)$ \\
\hline Alcohol (T51) & $1(0.8)$ & $1(0.6)$ & $12(0.5)$ & $3(0.3)$ & $17(0.4)$ \\
\hline \multicolumn{6}{|l|}{ Non-medical substances } \\
\hline $\begin{array}{l}\text { Organic solvents, hydrocarbons and metals, } \\
\text { etc (T52-T53, T56-T57) }\end{array}$ & $7(5.8)$ & $3(1.8)$ & $35(1.4)$ & $11(1.1)$ & $56(1.5)$ \\
\hline Corrosive substances (T54) & $13(10.7)$ & $3(1.8)$ & $80(3.1)$ & $35(3.6)$ & $131(3.4)$ \\
\hline Soaps and detergents (T55) & $8(6.6)$ & $0(0.0)$ & $32(1.2)$ & $4(0.4)$ & $44(1.2)$ \\
\hline Carbon monoxide (T58) & $1(0.8)$ & $2(1.2)$ & $60(2.3)$ & $24(2.5)$ & $87(2.3)$ \\
\hline Gases (T59) & $2(1.7)$ & $0(0.0)$ & $42(1.6)$ & $8(0.8)$ & $52(1.4)$ \\
\hline Pesticides (T60) & $14(11.6)$ & $17(10.4)$ & $839(32.7)$ & $414(42.4)$ & $1284(33.6)$ \\
\hline Seafood and food (T61-T62, T64) & $4(3.3)$ & $6(3.7)$ & $80(3.1)$ & $21(2.2)$ & $111(2.9)$ \\
\hline Contact with venomous animals (T63) & $9(7.4)$ & $11(6.7)$ & $305(11.8)$ & $187(19.2)$ & $512(13.4)$ \\
\hline Unspecified substances (T65) & $3(2.5)$ & $2(1.2)$ & $39(1.5)$ & $10(1.0)$ & $54(1.4)$ \\
\hline
\end{tabular}

then other drugs (353 cases, $13.8 \%$ ). In the $\geq 65$-year-old age group, pesticides were the most common poisoning substance ( 414 cases, $42.4 \%$ ), followed by contact with a venomous animal (187 cases, $19.2 \%)$ and then antiepileptic, sedative-hypnotic, antiparkinsonism drugs, and psychotropic drugs, not elsewhere classified (176 cases, $18.0 \%$ ) (table 2).

\section{Age differences in treatment outcomes}

A total of $3133(81.9 \%)$ of the 3826 patients survived the incident. By age group, $4(2.5 \%)$ of the 10-19-year-old patients died, $194(7.5 \%)$ of the 20-64-year-old patients, and $115(11.8 \%)$ of the $\geq 65$-year-old patients. The $\leq 9$ year-old age group showed the highest survival of all age groups, with $96.7 \%$ (117 patients) considered cured (table 3).

Gender differences in hospitalisation rate for intentional poisonings (per 100000 population)

A total of 2171 patients were hospitalised for intentional poisonings from 2005 to 2009, giving a hospitalisation rate of 0.705 (95\% CI 0.658 to 0.752 ) per 100000 population in men and 1.059 (95\% CI 1.001 to 1.116 ) per 100000 population in women (figure 1).

Gender differences in hospitalisation rates in different age groups for intentional poisonings (per 100000 population) Regarding intentional poisonings, 100 occurred in people $\geq 19$ years of age, 1620 in people $20-64$ years of age and 451 in people $\geq 65$ years of age. The hospitalisation rate per 100000 population was $0.166(95 \%$ CI 0.133 to 1.198$)$ in the $\leq 19$-year-old age group, 1.000 (95\% CI 0.952 to 1.049$)$ in the 20-64-year-old age group and 1.873 (95\% CI 1.700 to 2.046$)$ in the $\geq 65$-year-old age group. In the $\leq 19$-year-old age group, males had a lower hospitalisation rate per 100000 population $(0.092$, $95 \%$ CI 0.058 to 0.125$)$ than females $(0.248,95 \%$ CI 0.190 to 0.305 ). In 20-64-year-old age group, the hospitalisation rate for men $(0.749,95 \%$ CI 0.689 to 0.808$)$ was lower than that for women $(1.260,95 \%$ CI 1.182 to $1.337)$. In the $\geq 65$-year-old age group, men showed a higher hospitalisation rate $(2.350,95 \%$ CI 2.043 to

Table 3 Age differences in treatment outcomes $(\mathrm{N}=3826)$

\begin{tabular}{llllrl}
\hline & \multicolumn{2}{l}{ Age (years) } & & & \\
\cline { 2 - 5 } Treatment result & $\mathbf{5}$ & $\mathbf{1 0 - 1 9}$ & $\mathbf{2 0 - 6 4}$ & $\mathbf{2 6 5}$ & \multirow{2}{*}{ Total } \\
\hline Improved (cured) & $\mathbf{N}(\%)$ & $\mathbf{N}(\%)$ & $\mathbf{N}(\%)$ & $\mathbf{N}(\%)$ & $3133(81.9)$ \\
Not improved & $117(96.7)$ & $151(92.6)$ & $2111(82.3)$ & $754(77.2)$ & $225(5.9)$ \\
Not treated & $2(1.7)$ & $5(3.1)$ & $155(6.0)$ & $63(6.5)$ & $105(2.7)$ \\
Considered incurable & $2(1.7)$ & $3(1.8)$ & $73(2.8)$ & $27(2.8)$ & $32(0.8)$ \\
Death & $0(0.0)$ & $0(0.0)$ & $20(0.8)$ & $12(1.2)$ & $313(8.2)$ \\
Other & $0(0.0)$ & $4(2.5)$ & $194(7.5)$ & $115(11.8)$ & $18(0.5)$ \\
\hline
\end{tabular}




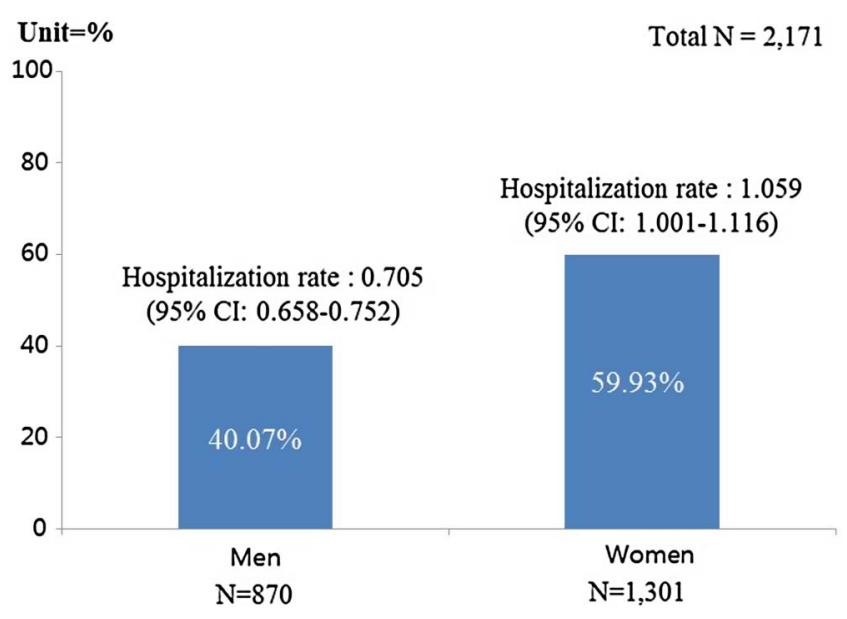

Figure 1 Gender differences in hospitalisation rates for intentional poisonings (per 100000 population).

2.656) than women $(1.556,95 \%$ CI 1.353 to 1.759$)$ (table 4).

Differences in causative substance between unintentional and intentional poisonings for each age group

In the $\leq 9$-year-old age group, the most common substances for unintentional poisonings was other drugs (T36-T39, T41, T44-T49), while antiepileptic, sedativehypnotic, antiparkinsonism drugs, and psychotropic drugs, not elsewhere classified were the most common for intentional poisonings. In the 10-19-year-old age group, other drugs (T36-T39, T41, T44-T49) were the most common agents for both intentional and unintentional poisonings. In both the 20-64-year-old and $\geq 65$-year-old age groups, contact with a venomous animal (T63) was the most common cause of unintentional poisoning, while pesticide-related poisonings (T60), antiepileptic, sedative-hypnotic, antiparkinsonism

Table 4 Gender differences in hospitalisation rates in different age groups for intentional poisonings (per $100000)(\mathrm{N}=2171)$

\begin{tabular}{|c|c|c|c|}
\hline & $\mathbf{N}$ & Per cent & $\begin{array}{l}\text { Hospitalisation rate } \\
\text { (per } 100000)\end{array}$ \\
\hline \multicolumn{4}{|c|}{$\leq 19$ years of age $(\mathrm{N}=100)$} \\
\hline Total & 100 & 100.0 & $0.166(95 \% \mathrm{Cl} 0.133$ to 1.198$)$ \\
\hline Male & 29 & 29.0 & $0.092(95 \% \mathrm{Cl} 0.058$ to 0.125$)$ \\
\hline Female & 71 & 71.0 & $0.248(95 \% \mathrm{Cl} 0.190$ to 0.305$)$ \\
\hline \multicolumn{4}{|c|}{$20-64$ years of age $(N=1620)$} \\
\hline Total & 1620 & 100.0 & $1.000(95 \% \mathrm{Cl} 0.952$ to 1.049$)$ \\
\hline Men & 615 & 38.0 & $0.749(95 \% \mathrm{Cl} 0.689$ to 0.808$)$ \\
\hline Women & 1005 & 62.0 & $1.260(95 \% \mathrm{Cl} 1.182$ to 1.337$)$ \\
\hline \multicolumn{4}{|c|}{$\geq 65$ years of age $(\mathrm{N}=451)$} \\
\hline Total & 451 & 100.0 & $1.873(95 \% \mathrm{Cl} 1.700$ to 2.046$)$ \\
\hline Men & 226 & 50.1 & 2.350 (95\% Cl 2.043 to 2.656$)$ \\
\hline Women & 225 & 49.9 & $1.556(95 \% \mathrm{Cl} 1.353$ to 1.759$)$ \\
\hline
\end{tabular}

*Three patients (one boy and two girls) who were below 9 years of age were included in the 10-19-year-old age group. drugs and psychotropic drugs, not elsewhere classified (T42, T43) were the most common substances in intentional poisonings (table 5 ).

\section{Age differences in causative substances for inpatient mortality}

Pesticides (T60) caused the most deaths in all age groups $(\leq 19,20-64, \geq 65)$. For the 20-64-year-old age group, corrosive substances (T54) and other and unspecified substances (T65) were the next most common causes of inpatient mortality. Corrosive substances (T54) and other drugs (T36-T39, T41, T44-T49), diuretics and other and unspecified drugs, medicaments and biological substances (T50) were other notable causes of inpatient mortality in the 65-year-old age group (table 6).

\section{DISCUSSION}

This study analysed nationally representative data from the Korea National Hospital Discharge In-Depth Injury Survey from 2005 to 2009, to investigate hospitalisation rates due to, and the characteristics of, poisoning incidents in Korea. The hospitalisation rate per 100000 population was higher for women (1.735) than for men (1.372). The $\geq 65$-year-old age group had the highest risk of poisoning incidents, with a hospitalisation rate of 4.053 , which was higher than that of the $\leq 9$-year-old (0.458), 10-19-year-old (0.481) and 20-64-year-old (1.584) age groups. The AAPCC reported in 2012 that of the 2275141 cases of poisoning in the USA, 1167584 $(51.32 \%)$ involved women and 1096954 (48.21\%) involved men. ${ }^{4}$ These results agree with a previous 2012 study by the Estonian National Poisoning Information Centre, which showed that there were more poisoning incidents in women (584 cases) than in men (495 cases). ${ }^{7}$ In Taiwan, 11523 patients were hospitalized for poisoning incidents between 2005 and 2007, giving a hospitalization rate of 16.83 per 100000 population; the hospitalisation rate was higher in women than in men, and the 45-69-year-old age group had the highest rate (52.85). ${ }^{17}$ However, we found two studies analysing poisoning patients where men outnumbered women. In the South Karnataka region of India, the ratio of men to women who visited a hospital following poisoning was 2.29:1, ${ }^{18}$ while men accounted for $71 \%$ of all poisoning incidents in the Kampala region of Uganda. ${ }^{19}$

The main causative substances were, in descending order, pesticides (T60) (33.6\%, 1284 cases), antiepileptic, sedative-hypnotic and antiparkinsonism drugs and psychotropic drugs, not elsewhere classified (T42, T43) $(22.1 \%, 847$ cases) and contact with venomous animals (T63) (13.4\%, 512 cases). In Morocco, according to CAPM (the Anti-Poison and Pharmacovigilance Centre of Morocco), the top three causative substances (responsible for $24.62 \%$ of poisoning incidents) were other drugs, gaseous substances and noxious substances eaten as food. ${ }^{20}$ 
Table 5 Differences in causative substances (agents) between unintentional and intentional poisonings for each age group ( $\mathrm{N}=3532)$

\begin{tabular}{|c|c|c|c|c|c|c|c|c|c|c|c|c|c|c|c|c|}
\hline \multirow[b]{4}{*}{ Causative substance (agent) } & \multicolumn{16}{|c|}{ Age (years) } \\
\hline & \multicolumn{4}{|c|}{$\leq 9(\mathrm{~N}=107)$} & \multicolumn{4}{|c|}{$10-19(N=148)$} & \multicolumn{4}{|c|}{$20-64(\mathrm{~N}=2400)$} & \multicolumn{4}{|c|}{$\geq 65(N=877)$} \\
\hline & \multicolumn{2}{|c|}{ Unintentional } & \multicolumn{2}{|c|}{ Intentional } & \multicolumn{2}{|c|}{ Unintentional } & \multicolumn{2}{|c|}{ Intentional } & \multicolumn{2}{|c|}{ Unintentional } & \multicolumn{2}{|c|}{ Intentional } & \multicolumn{2}{|c|}{ Unintentional } & \multicolumn{2}{|c|}{ Intentional } \\
\hline & $\bar{N}$ & Per cent & $\bar{N}$ & Per cent & $\overline{\mathbf{N}}$ & Per cent & $\bar{N}$ & Per cent & $\overline{\mathbf{N}}$ & Per cent & $\overline{\mathbf{N}}$ & Per cent & $\overline{\mathbf{N}}$ & Per cent & $\overline{\mathbf{N}}$ & Per cent \\
\hline \multicolumn{17}{|l|}{ Drugs, medicaments and biological substances } \\
\hline Other drugs (T36-T39, T41, T44-T49) & 24 & 23.1 & - & - & 18 & 35.3 & 49 & 50.5 & 47 & 6.0 & 278 & 17.2 & 26 & 6.1 & 15 & 3.3 \\
\hline Narcotics and psychodysleptics (T40) & - & - & - & - & - & - & - & - & - & - & 5 & 0.3 & - & - & 1 & 0.2 \\
\hline $\begin{array}{l}\text { Antiepileptic, sedative-hypnotic and antiparkinsonism drugs, } \\
\text { and psychotropic drugs, not elsewhere classified (T42, T43) }\end{array}$ & 14 & 13.5 & 2 & 66.7 & 5 & 9.8 & 24 & 24.7 & 64 & 8.2 & 510 & 31.5 & 41 & 9.6 & 108 & 23.9 \\
\hline $\begin{array}{l}\text { Diuretics and other and unspecified drugs, } \\
\text { medicaments and biological substances (T50) }\end{array}$ & 8 & 7.7 & - & - & 4 & 7.8 & - & - & 14 & 1.8 & 38 & 2.3 & 9 & 2.1 & 11 & 2.4 \\
\hline Alcohol (T51) & 1 & 1.0 & - & - & 1 & 2.0 & - & - & 9 & 1.2 & 2 & 0.1 & 3 & 0.7 & 0 & - \\
\hline \multicolumn{17}{|l|}{ Non-medical substances } \\
\hline $\begin{array}{l}\text { Organic solvents, hydrocarbons and metals, etc } \\
\text { (T52-T53, T56-T57) }\end{array}$ & 7 & 6.7 & - & - & 1 & 2.0 & - & - & 21 & 2.7 & 13 & 0.8 & 8 & 1.9 & 2 & 0.4 \\
\hline Corrosive substances (T54) & 11 & 10.6 & - & - & - & - & 3 & 3.1 & 22 & 2.8 & 53 & 3.3 & 16 & 3.8 & 16 & 3.5 \\
\hline Soaps and detergents (T55) & 8 & 7.7 & - & - & - & - & - & - & 12 & 1.5 & 20 & 1.2 & 2 & 0.5 & 2 & 0.4 \\
\hline Carbon monoxide (T58) & 1 & 1.0 & - & - & 1 & 2.0 & 1 & 1.0 & 40 & 5.1 & 16 & 1.0 & 18 & 4.2 & 4 & 0.9 \\
\hline Other gases, fumes and vapours (T59) & 2 & 1.9 & - & - & - & - & - & - & 40 & 5.1 & 2 & 0.1 & 6 & 1.4 & 0 & - \\
\hline Pesticides (T60) & 12 & 11.5 & 1 & 33.3 & 5 & 9.8 & 9 & 9.3 & 112 & 14.4 & 664 & 41.0 & 89 & 20.8 & 287 & 63.6 \\
\hline Seafood and food (T61-T62, T64) & 4 & 3.8 & - & - & 5 & 9.8 & - & - & 80 & 10.3 & - & - & 19 & 4.5 & 1 & 0.2 \\
\hline Contact with venomous animals (T63) & 9 & 8.7 & - & - & 11 & 21.6 & - & - & 304 & 39.0 & 1 & 0.1 & 186 & 43.7 & 1 & 0.5 \\
\hline Other and unspecified substances (T65) & 3 & 2.9 & - & - & - & - & 2 & 2.1 & 15 & 1.9 & 18 & 1.1 & 3 & 0.7 & 3 & 0.7 \\
\hline Total & 104 & 100 & 3 & 100 & 51 & 100 & 97 & 100 & 780 & 100 & 1620 & 100 & 426 & 100 & 451 & 100 \\
\hline
\end{tabular}


Table 6 Age differences in causative substances (agents) for inpatient mortality ( $N=313)$

\begin{tabular}{|c|c|c|c|c|}
\hline \multirow[b]{2}{*}{ Causative substance (agent) } & \multicolumn{3}{|c|}{ Age (years) } & \multirow[b]{2}{*}{ Total } \\
\hline & $\begin{array}{l}19^{*} \\
N(\%)\end{array}$ & $\begin{array}{l}20-64 \\
N(\%)\end{array}$ & $\begin{array}{l}\geq 65 \\
N(\%)\end{array}$ & \\
\hline \multicolumn{5}{|l|}{ Drugs, medicaments and biological substances } \\
\hline Other drugs (T36-T39, T41, T44-T49) & $0(0.0)$ & $1(0.5)$ & $2(1.7)$ & $3(1.0)$ \\
\hline $\begin{array}{l}\text { Antiepileptic, sedative-hypnotic and antiparkinsonism drugs, and } \\
\text { psychotropic drugs, not elsewhere classified (T42, T43) }\end{array}$ & $0(0.0)$ & $2(1.0)$ & $1(0.9)$ & $3(1.0)$ \\
\hline $\begin{array}{l}\text { Diuretics and other and unspecified drugs, medicaments and } \\
\text { biological substances (T50) }\end{array}$ & $0(0.0)$ & $0(0.0)$ & $2(1.7)$ & $2(0.6)$ \\
\hline Alcohol (T51) & $0(0.0)$ & $2(1.0)$ & $0(0.0)$ & $2(0.6)$ \\
\hline \multicolumn{5}{|l|}{ Non-medical substances } \\
\hline Organic solvents, hydrocarbons and metals, etc (T52-T53, T56-T57) & $0(0.0)$ & $0(0.0)$ & $1(0.9)$ & $1(0.3)$ \\
\hline Corrosive substances (T54) & $0(0.0)$ & $6(3.1)$ & $3(2.6)$ & $9(2.9)$ \\
\hline Carbon monoxide (T58) & $0(0.0)$ & $2(1.0)$ & $0(0.0)$ & $2(0.6)$ \\
\hline Pesticides (T60) & $4(100.0)$ & $175(90.2)$ & $105(91.3)$ & $284(90.7)$ \\
\hline Seafood and food (T61-T62, T64) & $0(0.0)$ & $1(0.5)$ & $0(0.0)$ & $1(0.3)$ \\
\hline Contact with venomous animals (T63) & $0(0.0)$ & $2(1.0)$ & $1(0.9)$ & $3(1.0)$ \\
\hline Other and unspecified substances (T65) & $0(0.0)$ & $3(1.5)$ & $0(0.0)$ & $3(1.0)$ \\
\hline Total & $4(100.0)$ & $194(100.0)$ & 115 (100.0) & $313(100.0)$ \\
\hline
\end{tabular}

Regarding causative substances by age group, other drugs (T36-T39, T41, T44-T49) ranked first in the $\leq 9$-year-old and $\leq 19$-year-old age groups with 28 $(23.1 \%)$ and 74 cases $(45.4 \%)$, respectively. Pesticides ranked first in both the 20-64-year-old and $\geq 65$-year-old age groups with 839 (32.7\%) and 414 cases $(42.4 \%)$, respectively.

The Swedish poisoning centre reported that the major causative substances in poisoning incidents in 2013 were, in descending order, chemical products $(42 \%)$, pharmaceuticals $(28 \%)$, plants $(11 \%)$, cosmetics $(8 \%)$ and tobacco $(4 \%){ }^{8}$ Causative substances in poisoning patients hospitalised in a tertiary hospital in Mumbai, India, were, in descending order, household products, pesticides and pharmaceuticals. ${ }^{21}$

As this study analysed causative substances using ICD codes, the results differ from those of poison information centres in other countries.

In this analysis of 2171 cases of intentional poisoning, men (0.705) had a lower hospitalisation rate than women (1.059) per 100000 population. This result is similar to the hospitalisation rate for total poisoning incidents, which was higher in women (1.735) than in men (1.372).

In a study of intentional poisoning deaths in southern India, the ratio of men to women was 2.7:1. ${ }^{13}$ The Taiwan National Poison Control Centre (PCC) reported a male: female ratio in unnatural poisoning deaths of 1.6:1 (67 men vs 42 women), which differs from the results of this study. ${ }^{22}$ However, numbers reported from China are similar, as women (2865 cases, 60.6\%) experienced unnatural poisoning deaths more frequently than men (1863 cases, $39.4 \%) .{ }^{23}$

This analysis of hospitalisation rates following intentional poisoning per 100000 population by age group, found an incidence rate of 0.166 among the $\leq 19$-year-old age group, 1.000 among the 20-64-year-old age group, and 1.873 among the $\geq 65$-year-old age group. An analysis of 250 cases of poisoning among those aged $\geq 65$ years identified 109 (43.6\%) intentional poisonings, ${ }^{22}$ while other studies found more than half of poisonings among those aged $\geq 65$ years were intentional. ${ }^{24} 25$ These results show that a high proportion of elderly citizens carry out intentional poisonings.

Additionally, analysis of intentional poisonings by gender for each age group in this study showed that intentional poisonings occurred more frequently among women in the $\leq 19$-year-old and 20-64-year-old age groups than in men of the same age. In the $\geq 65$-year-old group, however, more men than women had intentional poisoning. The finding that women aged 20-64 years experience more intentional poisonings than men of the same age contradicts the results of previous studies.

Analysis of data from KOSTAT (Statistics Korea) in 2002 showed suicide mortality rates per 100000 people in men aged between 35-64 years (37.8) were higher than in women of the same age (12.5). Among those aged 65 and older, the suicide rate was also higher among men (71.1) than among women (31.2) ${ }^{26}$ Studies suggest that the increased participation of women in economic activities can weaken social support and increase the suicide rate. ${ }^{27}$ Furthermore, the increase in male suicide rates may be due to changes in economic and social status caused by retirement. In this study, agricultural pesticides were most frequently used in intentional poisonings among individuals aged 20-64 and $\geq 65$ years. This finding coincides with the results of another study which identified agricultural pesticides as the main causative substances in intentional poisonings in China. ${ }^{23}$ 
The Taipei Poisoning Information Centre reported that benzodiazepines, insecticides, herbicides, warfarin and alcohol were the key causative substances ingested by patients aged 65 and older who visited an emergency room due to poisoning incidents. ${ }^{22}$

The majority of studies that have analysed poisoning incidents have reported that children aged 5 and younger have a high incidence of unintentional poisoning. ${ }^{457}$

The results of our study also demonstrate that incidents involving individuals $\leq 19$ years old were more likely to be registered as unintentional than intentional poisonings. Since relatively few children aged $\leq 5$ years were included in this study, all individuals aged $\leq 19$ years were classified into one group. We therefore believe that this finding is the result of the relatively low hospitalisation rate among children $\leq 5$ years old due to the low toxicity of the main causative substances reported in young children. ${ }^{28}$

Analysis of substances causing death in Taiwan by age showed that pesticides posed the highest risk for all age groups. Poisoning incidents involving methanol, herbicides and organophosphorus pesticides resulted in high inpatient mortality. A high Charlson Comorbidity Index (CCI) score, acute respiratory failure, alcohol and pesticide-related poisoning, procedures or surgery for poisoning incidents and short hospital stay were related to high inpatient mortality. ${ }^{17}$ Pesticides, animal and plant venom and gaseous products had the highest fatality rates in Morocco from 2013 to $2014 .^{20}$

Analysis of national mortality (1999-2008) and hospital discharge (2000-2009) data from New Zealand showed that two-thirds of causative substances in intentional poisonings $(92.7 \%$ of which involved carbon monoxide) were other gases and vapours, and one-third were pharmaceuticals (ICD-10 codes X60-X64). Antiepileptic, sedative-hypnotic, antiparkinsonism and psychotropic drugs, not elsewhere classified were responsible for $17.9 \%$ of poisonings. Causative substances for unintentional poisonings were mostly pharmaceuticals (codes X40-X44), of which $50.0 \%$ were related to narcotics and psychotropic drugs, not elsewhere classified (codeine or morphine), $44.1 \%$ were related to methadone. $18.1 \%$ of unintentional poisonings were related to alcohol. ${ }^{29}$

The WHO recommends that all countries provide 24/7 poisoning advice and related information, and also operate poisoning management, information and research centres. ${ }^{30}$ The US manages 55 national poisoning management and information centres through the AAPCC, providing 24-hour poison information to medical staff and the general public by phone free of charge. ${ }^{31}$ Japan has provided 24-hour information to the general public and professionals since 1986 through the Japan Poison Information Center in Osaka. ${ }^{32}$ In the western Pacific region, Australia, Hong Kong, Japan, Malaysia, Mongolia, the Philippines and Vietnam operate poisoning management and information centres. ${ }^{33}$ However, Korea lacks such centres which could administer a national poisoning surveillance system. $^{34} 35$

A large number of studies have reported that fatal poisoning incidents can be reduced in children through preventive education. ${ }^{36}$ The AAPCC reported that the operation of a poisons centre reduced the number of poisoning patients requiring hospitalisation by $12.0 \%$, and reduced medical expenses by $24.0 \%$. The number of unnecessary emergency room visits also declined by $24.0-37.0 \%{ }^{37}$ These results indicate the need for a cost effectiveness analysis of the treatment of poisoning patients and a trend analysis of poisoning incidents nationwide, in order to provide data for a Korean poisoning information and management centre.

A limitation of this study is the exclusion of poisoning patients who visited medical institutions with fewer than 100 beds. Nevertheless, the in-depth discharge survey data allowed causative substances in poisoning incidents to be analysed by age group and intentionality, and is representative at a national level.

\section{CONCLUSION}

This study analysed poisoning incidents by gender and age group, causative substances by age group, and intentionality. Findings confirmed that poisoning incidence rates vary by age group and gender. Men had a higher incidence of intentional poisoning than women, particularly among those aged 65 and older, which differs from the results of previous studies. The findings of this study are significant in that they could be used as a basis for establishing a national poisons centre in Korea, as well as providing policy data for the formulation of preventive policies related to poisoning.

Contributors J-WC and KK conducted overall research. ESL analysed the Korea National Hospital Discharge In-Depth Injury Survey data from 2005 to 2009. MP and MSK analysed the survey data. KK and JWC were responsible for writing the paper. All authors were involved in study conception and design, and reviewed the final draft of the manuscript.

Competing interests None declared.

Provenance and peer review Not commissioned; externally peer reviewed.

Data sharing statement No additional data are available.

Open Access This is an Open Access article distributed in accordance with the Creative Commons Attribution Non Commercial (CC BY-NC 4.0) license, which permits others to distribute, remix, adapt, build upon this work noncommercially, and license their derivative works on different terms, provided the original work is properly cited and the use is non-commercial. See: http:// creativecommons.org/licenses/by-nc/4.0/

\section{REFERENCES}

1. Lall SS, Peshin SS, Seth SD. Acute poisonings: a ten-year retrospective hospital based study. Ann Natl Acad Med 1994;30:35-44.

2. Senanayake N, Peiris $\mathrm{H}$. Mortality due to poisoning in a developing agricultural country: trends over 20 years. Hum Exp Toxicol 1995;14:808-11. 
3. Kim KH, Song DJ, Park MS, et al. Necessity and the strategy to establish a national poison center in Korea: through needs survey analysis and database status for chemical accident emergency respond information system. J Korean Med Assoc 2013;56:724-35 [in Korean]

4. Mowry JB, Spyker DA, Cantilena LR Jr, et al. 2012 Annual Report of the American Association of Poison Control Centers' National Poison Data System (NPDS): 30th Annual Report. Clin Toxicol (Phila) 2013;51:949-1229.

5. Public Health England. National Poisons Information Service Report 2012/13. 2013. http://www.npis.org/NPISAnnualReport2012-13.pdf (accessed 5 Mar 2014).

6. Poisons Information Centre of Ireland. Annual Report 2012. Dublin, Ireland: Beaumont Hospital. http://www.drugsandalcohol.ie/21307/1/ 2012AnnualReport.pdf (accessed 15 Jan 2014).

7. Oder M, Pold K. Estonian experience on establishment of a modern national poison information centre: one-year profile of phone calls in 2012. Asia Pac J Med Toxicol 2013;2:42-7.

8. Swedish Poisons Information Centre. Annual Report 2014 (accessed 2 Nov 2015).

9. Shin SD, Suh GJ, Rhee JE, et al. Epidemiologic characteristics of death by poisoning in 1991-2001 in Korea. J Korean Med Sci 2004;19:186-94.

10. Choi YC, Kim YH, Ko YS, et al. Economic burden of acute pesticide poisoning in South Korea. Trop Med Int Health 2012;17:1534-43.

11. Ko YS, Kim HJ, Cha ES, et al. Emergency department visits due to pesticide poisoning in South Korea, 2006-2009. Clin Toxicol 2012;50:114-19.

12. Park JH, Shin SD, Song KJ, et al. Epidemiology and outcomes of poisoning-induced out-of-hospital cardiac arrest. Resuscitation 2012;83:51-7.

13. Kumar TS, Kanchan T, Yoganarasimha K, et al. Profile of unnatural deaths in Manipal, Southern India 1994-2004. J Clin Forensic Med 2006;13:117-20.

14. The Korea Centers for Disease Control and Prevention. Discharge Injury In-Depth Survey database [in Korean]. http://cdc.go.kr/CDC/ contents/CdcKrContentView.jsp?cid=62109\&menulds=HOME001MNU1130-MNU1110-MNU1878-MNU1888 (accessed 10 Sep 2015)

15. Do SR, Kim JS, Kang SH, et al. Korea Institute for Health and Social Affairs. A Study for Improving the Production of Health Care Use Statistics. 2012. https://www.kihasa.re.kr/html/jsp/english/public/view. jsp?bid=30\&ano=645 (Korean).

16. World Health Organization (WHO). International Statistical Classification of Diseases and Related Health Problems 10th Revision. 2014. http://apps.who.int/classifications/apps/icd/ icd10online2007/index.htm?gt36.htm (accessed 5 Mar 2014).

17. Chien WC, Chung $\mathrm{CH}$, Lin $\mathrm{CH}$, et al. A nationwide evidence-based study of factors associated with hospitalizations due to unintentional poisoning and poisoning mortality in Taiwan. Int $J$ Inj Contr Saf Promot 2013;20:295-301.

18. Unnikrishnan B, Singh B, Rajeev A. Trends of acute poisoning in south Karnataka. Kathmandu Univ Med J 2005;3:149-54.

19. Malangu N. Acute poisoning at two hospitals in Kampala-Uganda. $J$ Forensic Leg Med 2008;15:489-92.
20. Hanane C, Naima R, Mohamed B, et al. Toxicovigilance Rapports General et Specifiques Annee. 2014. http://www.capm.ma/Doc/ revues/Revue_Toxicologie_Maroc_n23_2014_Rapports_TV.pdf (accessed 27 Oct 2015)

21. Patil S, Gautam M, Nadkarni N, et al. Gender differences in clinicoepidemiological features of vitiligo: a cross-sectional analysis. ISRN Dermatol 2014;13:186-97.

22. $\mathrm{Hu} \mathrm{YH}, \mathrm{Chou} \mathrm{HL,} \mathrm{Lu} \mathrm{WH,} \mathrm{et} \mathrm{al.} \mathrm{Features} \mathrm{and} \mathrm{prognostic} \mathrm{factors} \mathrm{for}$ elderly with acute poisoning in the emergency department. J Chin Med Assoc 2010;73:78-87.

23. Zhang $\mathrm{X}$, Li HS, Zhu QH, et al. Trends in suicide by poisoning in China 2000-2006: age, gender, method, and geography. Biomed Environ Sci 2008;21:253-6.

24. Cassidy N, Lee SKK, Donegan CF, et al. Poisoning in older adults: the experience of the National Poisons Information Centre. Ir Med J 2008;101:268-70.

25. Karbakhsh M, Zandi NS. Pattern of poisoning in the elderly: an experience from Tehran. Clin Toxicol (Phila) 2008;46:211-17.

26. Khang YH, Lynch JW, Kaplan, GA. Impact of economic crisis on cause-specific mortality in South Korea. Int J Epidemiol 2005;34:1291-301.

27. Chuanc HL, Huang WC. Economic and social correlates of regional suicide rates: a pooled cross-section and time-series analysis. J Socio Econ 1997;26:277-89.

28. Polivka BJ, Casavant M, Baker SD. Factors associated with healthcare visits by young children for nontoxic poisoning exposures. J Community Health 2010;35:572-8.

29. Peiris-John R, Kool B, Ameratunga S. Fatalities and hospitalisations due to acute poisoning among New Zealand adults. Intern Med $J$ 2014;44:273-81.

30. World Health Organization (WHO). Guidelines for poison control. 2014. http://www.who.int/ipcs/publications/training_poisons/ guidelines_poison_control/en/ (accessed 5 Mar 2014).

31. American Association of Poison Control Centers (AAPCC). http:// www.aapcc.org/ (accessed 10 Apr 2014).

32. Japan Poison Information Center. http://www.j-poison-ic.or.jp/ homepage.nsf (accessed 15 Jan 2014).

33. World Health Organization (WHO). World directory of poison centers. Geneva: World Health Organization, 2014. http://apps.who. int/poisoncentres (accessed 5 Mar 2014).

34. Kim KH, Song DJ, Yu MH, et al. Hazard classification of household chemical products in Korea according to the globally harmonized system of classification and labeling of chemicals. Ann Occup Environ Med 2013;25:11.

35. Meyer S, Eddleston M, Bailey B, et al. Unintentional household poisoning in children. Klin Padiatr 2007;219:254-70.

36. Miller TR, Lestina DC. Costs of poisoning in the United States and savings from poison control centers: a benefit-cost analysis. Ann Emerg Med 1997;29:239-45.

37. American Association of Poison Control Centers (AAPCC). Value of the poison center system. Alexandria: American Association of Poison Control Centers. https://aapcc.s3.amazonaws.com/files/ library/Value_of_the_Poison_Center_System_FINAL_9_26_2012_-_ FINAL_FINAL_FINAL.pdf (accessed 10 Apr 2014). 